\title{
Stimulation of eosinophil IgE low-affinity receptor leads to increased adhesion molecule expression and cell migration
}

\author{
S. Lantero*, G. Alessandri**, D. Spallarossa*, L. Scarso***, G.A. Rossi*
}

Stimulation of eosinophil IgE low-affinity receptor leads to increased adhesion molecule expression and cell migration. S. Lantero, G. Alessandri, D. Spallarossa, L. Scarso, G.A. Rossi. (C) ERS Journals Ltd 2000.

ABSTRACT: Immunoglobulin binding on eosinophil surface receptors results in activation of these cells. Evaluating blood eosinophils from atopic subjects, it was investigated whether ligation of immunoglobulin $\mathrm{E}$ low-affinity receptor (Fec RII/ CD23) with specific monoclonal antibodies (Mabs) resulted in enhanced eosinophil migration and adhesion molecule expression.

Eosinophils from 20 subjects with allergic asthma (atopic individuals) and nine nonatopic normal individuals (controls) were purified using Percoll gradients. The effect of antihuman CD23 Mabs on: 1) eosinophil migration through human umbilical vein endothelial cells (HUVECs); and 2) eosinophil expression of the adhesion molecules leukocyte function-associated antigen-1 (LFA-1, CD11a/CD18), macrophage antigen-1 (Mac-1, CD11b/CD18) and very late activation antigen-1 (VLA-4, CD49d/CD29) was evaluated by specific Mab staining and flow cytometric analysis.

As compared to controls, freshly isolated eosinophils from atopic individuals showed enhanced migration through HUVECs $(p<0.05)$ and increased LFA-1 expression $(p<0.01)$, but similar Mac-1 and VLA-4 expression ( $>0.1$ for both). In both controls and atopic individuals, eosinophil incubation with antihuman CD23 Mabs induced a dose-dependent increase in cell migration through HUVECs, significant at antihuman CD23 Mab concentrations of $5 \mu \mathrm{g} \cdot \mathrm{mL}^{-1}(p>0.05$ for all). Similarly, incubation of the cells with antihuman CD23 Mabs induced dose-dependent upregulation of LFA-1 and Mac-1 expression, whereas no changes in VLA-4 expression were observed $(p>0.1)$. Finally, the enhanced eosinophil migration induced by antihuman CD23 Mab stimulation was significantly inhibited by antihuman LFA-1 $(84 \pm 14 \%(\operatorname{mean} \pm S E M) ; p<0.01)$ and VLA-4 Mabs $(47 \pm 15 \% ; p<0.05)$ but not by antihuman Mac-1 Mabs (p>0.1).

In both atopic and control subjects, immunoglobulin $E$, low-affinity receptor stimulation induces functional changes in esinophils characterized by increased eosinophil migration associated with enhanced late function antigen-1 and Mac-1 expression.

Eur Respir J 2000; 16: 940-946.

\author{
*Pulmonary Division and ***Blood Bank \\ G. Gaslini Institute, and **Dept of Cell \\ Biology, National Cancer Research \\ Institute, Genoa, Italy. \\ Correspondence: G.A. Rossi \\ Pulmonary Division \\ G. Gaslini Institute \\ Largo G. Gaslini 5 \\ 16147 Genoa \\ Italy \\ Fax: 390103776590 \\ Keywords: Adhesion molecules \\ atopy \\ cell migration \\ eosinophils \\ immunoglobulin E low-affinity receptor
}

Received: December 291999

Accepted after revision August 82000

This study was supported by grant "Ricerca Finalizzata" No. ICS 34.1/RF 93.48 from the Ministero della Sanità, Rome, Italy.
In allergic asthma, exposure to the sensitizing allergen leads to eosinophil recruitment and activation. Eosinophils have the potential to injure human lung tissues and their presence in the airway mucosa has been associated with degree of airflow limitation and morphological derangement of the bronchial epithelium. The current thought is, therefore, that eosinophils act as major effector elements in the pathogenesis of allergic asthma $[1,2]$.

Eosinophil recruitment is a complex mechanism, which includes the expression of surface adhesion molecules on circulating cells, able to interact with their counterreceptors, expressed on vascular endothelial cells [3]. It has been demonstrated that T-helper 2 (Th2) cytokines (interleukin (IL)-3, IL-5 and granulocyte-macrophage colony-stimulating factor) and chemokines (eotaxin and regulated on activation, normal T-cell expressed and secreted are able to not only prime and activate eosinophils but also increase cell surface receptor and adhesion molecule expression on these cells [3-7]. In atopic asthma, a condition characterized by increased secretion of Th2 cytokines and chemokines, the expression of adhesion molecules on the eosinophil cell membrane is increased and appears to be involved in cell migration [8].

Besides inflammatory mediators, stimulation of surface receptors specific for immunoglobulins (Igs) also plays a significant role in modulating cell function [9, 10]. Eosinophils are able to bind IgE through highand low-affinity receptors (FceRI and FceRII or CD23 respectively) $[11,12]$, and, although the specific functions of FceRI and FceRII are still controversial [10, $12]$, it has been demonstrated that anti-CD23 monoclonal antibodies (Mabs) or IgE/anti-IgE immune complexes are able to increase hydrogen peroxide and tumour necrosis factor production by eosinophils [9]. The observation that allergic patients with a high level of allergen-specific IgE show increased expression of eosinophil adhesion molecules and the reported correlation between serum allergen-specific IgE, the number of 
eosinophils infiltrating the airways and the severity of asthma [8] suggest that FceRII may modulate eosinophil locomotion. Against this background, the present study was designed to evaluate in vitro whether stimulation of the FceRII by antihuman CD23 Mabs enhanced eosinophil migration through human umbilical vein endothelial cells (HUVECs) and expression of the adhesion molecules leukocyte function-associated antigen-1 (LFA-1, CD11a/CD18), macrophage antigen-1 (Mac-1, CD11b/ CD18) and very late antigen-1 (VLA-4, CD49d/CD29) involved in eosinophil transendothelial migration.

\section{Materials and methods}

\section{Reagents}

Complete medium comprised Roswell Park Memorial Institute (RPMI)-1640 medium (PAA, Linz, Austria), $50 \mathrm{U} \cdot \mathrm{mL}^{-1}$ penicillin, $50 \mathrm{mg} \cdot \mathrm{mL}^{-1}$ streptomycin, $2 \mathrm{mM}$ L-glutamine, $2 \mathrm{mg} \cdot \mathrm{mL}^{-1} \mathrm{NaHCO}_{3}, 1 \times$ nonessential amino acids, 5\% foetal calf serum (FCS) (Flow ICN, Irvine, UK) and $2 \mathrm{mM}$ 2-mercaptoethanol (Sigma Chemical Co., St Louis, MO, USA). Endothelial basal medium (EBM) was obtained from Dilco Laboratories (Milan, Italy). Trypan blue and phosphate-buffered saline (PBS) were from Flow ICN Dextran (molecular weight 70,000), $10 \times$ Hank's $^{\prime}$ balanced salt solution (HBSS), sodium azide and complement factor 5a (C5a) were obtained from Sigma Chemical Co. Heparin was from Parke-Davis S.p.A. (Milan, Italy), Percoll from Pharmacia (Uppsala, Sweden), and Diff-Quik from Merz+Dade (Dudingen, Switzerland). Mouse antihuman IgG1 Mabs to CD23 and CD45; mouse antihuman IgG1 Mab to CD11a, conjugated to R-phycoerythrin (PE) and unconjugated (clone B-B15); mouse antihuman IgG1 to $\mathrm{CD} 3$ PE-conjugated and unconjugated, as isotype control; and antihuman CD11b, and CD49d, both PEconjugated and unconjugated, were obtained from Serotec (Oxford, UK), mouse antihuman IgG1 Mab to CD16b conjugated to fluorescein isothiocyanate from Ortho Diagnostic System (Milan, Italy) and PE-conjugated mouse antihuman IgG1 Mab to CD23 from Becton Dickinson (Milan, Italy).

\section{Population}

Eosinophils were obtained from nine nonatopic normal individuals (controls) (6-11 yrs; seven male and two female) and 20 atopic asthmatic subjects sensitized to house dust mites, as demonstrated by skin-prick test and radioallergosorbent test (Pharmacia) (atopic individuals) (6-14 yrs; 15 male and 5 female) (table 1). Asthma was defined according to the criteria of the American Thoracic Society [13]. Controls and atopic individuals had not suffered from respiratory infections in the previous 4 weeks and were not under any treatment other than $\beta_{2}-$ stimulants on an "as necessary" basis. The study was approved by the G. Gaslini Institute Ethical Committee and parents or tutors of all subjects gave their informed consent.

Because of the relatively high numbers of cells required, eosinophils collected from different individuals were often used to perform different kinds of experiment, as indicated below.
Table 1. - Characteristics of atopic individuals and controls

\begin{tabular}{|c|c|c|c|c|c|}
\hline Subject No. & Sex & $\begin{array}{l}\text { Age } \\
\text { yrs }\end{array}$ & $\begin{array}{c}\text { Eosinophils } \\
\%\end{array}$ & $\begin{array}{l}\text { PRIST } \\
\mathrm{kU} \cdot \mathrm{L}^{-1}\end{array}$ & $\begin{array}{l}\text { RAST } \\
\mathrm{kU} \cdot \mathrm{L}^{-1}\end{array}$ \\
\hline \multicolumn{6}{|l|}{ Control* } \\
\hline 1 & M & 6 & 1.7 & - & - \\
\hline 2 & M & 6 & 1.8 & - & - \\
\hline 3 & M & 11 & 2.1 & - & - \\
\hline 4 & M & 6 & 1.0 & - & - \\
\hline 5 & M & 11 & 3.2 & - & - \\
\hline 6 & M & 6 & 2.4 & - & - \\
\hline 7 & M & 8 & 0.9 & - & - \\
\hline 8 & F & 6 & 2.7 & - & - \\
\hline 9 & F & 9 & 5.4 & - & - \\
\hline \multicolumn{6}{|c|}{ Atopic individuals* } \\
\hline 1 & M & 6 & 4.8 & 165 & 76.1 \\
\hline 2 & M & 11 & 5.7 & 1431 & $>100$ \\
\hline 3 & M & 6 & 3.9 & 210 & 33.6 \\
\hline 4 & M & 6 & 4.8 & 115 & 49.5 \\
\hline 5 & $\mathrm{~F}$ & 6 & 6.2 & 602 & $>100$ \\
\hline 6 & M & 10 & 8.9 & 316 & 67.0 \\
\hline 7 & F & 6 & 10.9 & 381 & $>100$ \\
\hline 8 & M & 6 & 6.4 & 240 & $>100$ \\
\hline 9 & M & 11 & 6.0 & 405 & $>100$ \\
\hline 10 & M & 8 & 14.8 & 411 & 59.5 \\
\hline 11 & M & 7 & 11.4 & 290 & 63.0 \\
\hline 12 & M & 14 & 19.2 & 857 & $>100$ \\
\hline 13 & M & 9 & 4.3 & 465 & 61.4 \\
\hline 14 & $\mathrm{~F}$ & 12 & 5.7 & 580 & 13.9 \\
\hline 15 & M & 8 & 13.0 & 1842 & $>100$ \\
\hline 16 & M & 12 & 6.5 & 323 & 82.1 \\
\hline 17 & M & 6 & 11.4 & 504 & $>100$ \\
\hline 18 & $\mathrm{~F}$ & 12 & 2.4 & 158 & 76.4 \\
\hline 19 & $\mathrm{~F}$ & 6 & 6.3 & 290 & 58.3 \\
\hline 20 & M & 6 & 4.1 & 171 & 59.4 \\
\hline
\end{tabular}

*: atopic individuals but not controls were sensitized to house dust mites. SPT: skin-prick test; RAST: radioallergosorbent test; M: male; F: female; PRIST: paper radio immunosorbent test.

\section{Eosinophil purification}

Isolation of blood eosinophils was performed on discontinuous Percoll gradients, as previously described [14]. Briefly, to $10 \mathrm{~mL}$ heparinized blood, an equal volume of $6 \%$ dextran in $0.9 \% \mathrm{NaCl}$ was added, mixed gently and incubated at $37^{\circ} \mathrm{C}$. After 30-40 min, the upper phase was collected, washed once in PBS, resuspended in $1.5 \mathrm{~mL} 1.070 \mathrm{~g} \cdot \mathrm{mL}^{-1}$ Percoll containing 5\% FCS and layered on a discontinuous Percoll gradient with the following volumes $(\mathrm{mL})$ and densities $\left(\mathrm{g} \cdot \mathrm{mL}^{-1}\right)$ respectively: 1.5, 1.100; 3, 1.090: 3, 1.085; and 3, 1.080 [14]. The Percoll gradient densities were obtained by mixing nine parts of Percoll with one part of $10 \times$ HBSS and then diluting the $90 \%$ Percoll solution with $1 \times$ HBSS containing 5\% FCS. The normodense eosinophils recovered from $1.090-1.095 \mathrm{~g} \cdot \mathrm{mL}^{-1}$ Percoll were washed twice in PBS and resuspended at $1 \times 10^{6}$ eosinophils $\cdot \mathrm{mL}^{-1}$ in complete medium. The hypodense population represented only a small proportion of the total eosinophil population and, because of the low number of cells, could not be used to perform any study. The eosinophils recovered were $70-80 \%$ pure (as established by Diff-Quik staining, with neutrophils as contaminant) and 90\% viable, as determined by trypan blue dye exclusion test. 
Evaluation of eosinophil migration through endothelial cell layer

The day before the assay, $5 \times 10^{5}$ HUVECs were seeded on polycarbonate membranes with $5-\mu \mathrm{m}$ pores coated with type I collagen, in order to reach confluence on the day of the assay, and incubated in EBM under $5 \% \mathrm{CO}_{2}$ conditions at $37^{\circ} \mathrm{C}$ [15]. On the day of the assay, the membranes were placed in Boyden chemotaxis chambers with the HUVEC side up. The lower wells were filled with $50 \mu \mathrm{L}$ complete medium, to evaluate random migration, or with $0.1 \mu \mathrm{g} \cdot \mathrm{mL}^{-1} \mathrm{C} 5 \mathrm{a}$ in complete medium, as eosinophil chemoattractant [16]. The C5a concentration had been established in previous dose/response experiments on eosinophils from both controls and atopic individuals. Unstimulated or CD23-stimulated eosinophils (see below) in $100 \mu \mathrm{L}$ complete medium at a concentration of $1 \times 10^{6}$ cells $\cdot \mathrm{mL}^{-1}$ were seeded in the upper chamber compartments, on the HUVEC side. After a 3-h incubation under $5 \% \mathrm{CO}_{2}$ conditions at $37^{\circ} \mathrm{C}$, the membranes were detached, the HUVECs peeled off the upper side and the eosinophils that had migrated through the HUVECs to the lower side were fixed, stained with DiffQuick and counted using a light microscope. All the chemotactic conditions were tested in duplicate and the data expressed as number of eosinophils migrated in 10 high-power fields $(\mathrm{HPFs}$, magnification $\times 400)$ [16].

\section{Evaluation of membrane molecule expression on eosinophils}

LFA-1 (CD11a/CD18), Mac-1 (CD11b/CD18), VLA-4 (CD49d/CD29) and FceRII (CD23) expression on eosinophils from controls and atopic individuals was evaluated by staining with specific Mabs and flow cytometry. Cells were washed once in PBS, resuspended in $100 \mu \mathrm{L}$ PBS containing 2\% FCS and $0.5 \mu \mathrm{g} \cdot \mathrm{mL}^{-1} \mathrm{NaN}_{3}$ (staining medium), and stained with $10 \mu \mathrm{g} \cdot \mathrm{mL}^{-1}$ FITC-conjugated antihuman CD16b (green fluorescence, to distinguish by two-colour flow cytometry contaminant CD16b+ neutrophils from CD16b-eosinophils), [4] and $10 \mu \mathrm{g} \cdot \mathrm{mL}^{-1} \mathrm{PE}-$ conjugated antihuman CD11a, CD11b, CD49d, CD23 or CD3 (mouse IgG isotype control) (red fluorescence). In order to test the possibility that the process of eosinophil separation could increase the expression of some membrane receptors detected by flow cytometry [17], whole-blood staining was also performed in five atopic individuals and in three controls. Unstimulated or CD23stimulated eosinophils (see below) were then incubated for $1 \mathrm{~h}$ at $4^{\circ} \mathrm{C}$, washed twice in staning medium and resuspended at $5 \times 10^{5}$ cells $\cdot \mathrm{mL}^{-1}$ in $200 \mu \mathrm{L}$ PBS.

The red fluorescence intensity of the CD16b- cells (eosinophils) was obtained for 10,000 acquired cells using flow cytometry (FACScan; Becton Dickinson, Milan, Italy) and expressed as mean fluorescence channel (MFC) [18]. To compare the fluorescence intensity of different samples, the cells were acquired under identical logarithmic amplifier settings and analysed using Lysis II software (Becton Dickinson). After conversion to linear fluorescence intensity units the mean background obtained using the control antibody (PE-conjugated antihuman Mab to CD3) was subtracted from the mean fluorescence intensity of the specifically stained cells to obtain a linear function of fluorescence intensity over a wide range [19].

Eosinophil stimulation by immunoglobulin E lowaffinity receptor ligation with antihuman monoclonal antibody to CD23

Eosinophils from eight controls and 14 atopic individuals were resuspended in complete medium, seeded in 96-well U-bottomed plates (Costar, Cambridge, MA, USA) in a total volume of $100 \mu \mathrm{L}$ at $10^{\circ}$ eosinophils $\cdot \mathrm{mL}^{-1}$. Flow cytometry on CD23-stained eosinophils was performed before the assays to demonstrate the expression of FceRII on eosinophils of all subjects who were the source of cells for these experiments. Preliminary sets of experiments demonstrated that the length of time required to detect antihuman Mab to CD23-induced modification of adhesion molecule expression on eosinophils was $\sim 3 \mathrm{~h}$. The cells were, therefore, incubated with different concentrations of antihuman CD23 (0.5, 2.5, 5,10 or $20 \mu \mathrm{g} \cdot \mathrm{mL}^{-1}$ ) or, as control, antihuman Mab to $\mathrm{CD} 45$, which recognizes all leukocytes for $3 \mathrm{~h}$ under $5 \%$ $\mathrm{CO}_{2}$ conditions at $37^{\circ} \mathrm{C}$. After incubation, chemotactic activity and expression of adhesion molecules were evaluated as described above. To evaluate the functional role of the different adhesion molecules in cell migration, eosinophils were preincubated in the presence or absence of antihuman Mabs to CD11a, CD11b or CD49d or mouse $\mathrm{IgG}$, as isotype control, $\left(10 \mu \mathrm{g} \cdot \mathrm{mL}^{-1}\right)$ for $30 \mathrm{~min}$ under $5 \% \mathrm{CO}_{2}$ conditions at $37^{\circ} \mathrm{C}$ prior to the chemotaxis assay.

\section{Statistical analysis}

Data are expressed as mean \pm SEM. Statistical comparisons between different cell culture conditions were performed using an unpaired t-test or the Mann-Whitney U-test, when appropriate [20]. Data were considered significant at a $\mathrm{p}$-value of $<0.05$.

\section{Results}

Eosinophil migration through human umbilical vein endothelial cells and adhesion molecule expression

In both controls and atopic individuals, C5a significantly enhanced eosinophil locomotion above random migration levels. However, as compared to controls, eosinophils from atopic individuals showed greater migration through HUVECs towards C5a (16 44 versus $22 \pm 4$ eosinophils $\cdot 10 \mathrm{HPF}^{-1}, \mathrm{p}<0.05$ ) (fig. 1a). In addition, as compared to controls, increased membrane expression of LFA-1 was detected on eosinophils from atopic individuals ( $33 \pm 6$ versus $62 \pm 5 \mathrm{MFC}, \mathrm{p}<0.01$ ), whereas there were no difference in the expression of Mac-1 and VLA-4 ( $>0$.1) (fig. 1b). No staining was observed with the mouse IgG isotype control (data not shown). The process of eosinophil separation did not appear to influence the expression of adhesion molecules, since no differences in the levels of LFA-1, Mac-1 and VLA-4 expression were found when eosinophils in unseparated whole-blood samples or after discontinuous Percoll gradient separation, in both atopic individuals and controls ( $\mathrm{p}>0.1$ for both), were evaluated (data not shown). 
a)

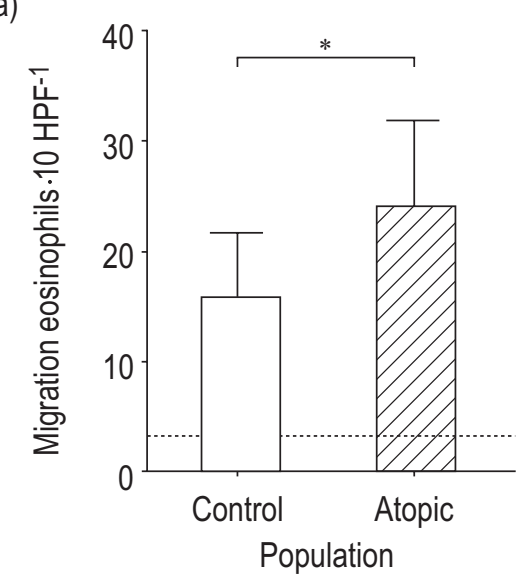

b)

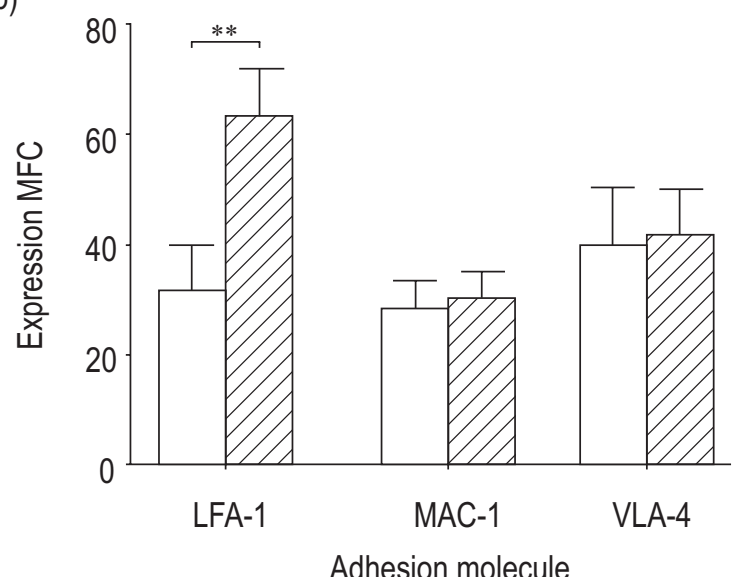

Fig. 1. - Functional and phenotypic evaluation of blood eosinophils: a) migration of eosinophils from eight controls $(\square)$ and 14 atopic individuals $(\mathbb{Z})$ through human umbilical vein endothelial cells towards $0.1 \mu \mathrm{g} \cdot \mathrm{mL}^{-1}$ complement factor 5a (- - -: random migration); and b) constitutive expression of late function antigen-1 (LFA-1), (Mac-1) and very late activation antigen-4 (VLA-4) by circulating eosinophils from nine controls and 20 atopic individuals. Data are presented as mean \pm SEM. HPF: high-power field; MFC: mean fluorescence channel. *: $\mathrm{p}<0.05 ;{ }^{* *}$ : $\mathrm{p}<0.01$.

\section{Immunoglobulin E low-affinity receptor ligation activity on eosinophils}

All of the atopic individuals and most of the controls (six of nine) expressed low but detectable levels of CD23 $(p<0.05$ for both versus CD3, the isotype control). The mean expression level was slightly but not significantly higher in atopic individuals compared to controls $(\mathrm{p}>0.1)$ (fig. 2). Incubation of eosinophils with antihuman Mabs to $\mathrm{CD} 23$ induced a dose-dependent increase in cell migration towards $0.1 \mu \mathrm{g} \cdot \mathrm{mL}^{-1} \mathrm{C} 5 \mathrm{a}$ in both controls and atopic individuals. In contrast, no changes in cell locomotion through HUVECs were detected when eosinophils were cultured in the presence of different concentrations of the control antihuman Mabs to CD45 ( $p>0.05$ for all) (fig. 3). The increase in cell migration induced by antihuman Mabs to CD23 reached statistical significance at Mab concentrations of $5 \mu \mathrm{g} \cdot \mathrm{mL}^{-1}$ in both controls $(\mathrm{p}<0.01)$ and atopic individuals $(\mathrm{p}<0.05)$. Interestingly, eosinophil stimulation with the antihuman Mab to CD23 also induced a dose-dependent increase in LFA-1 and

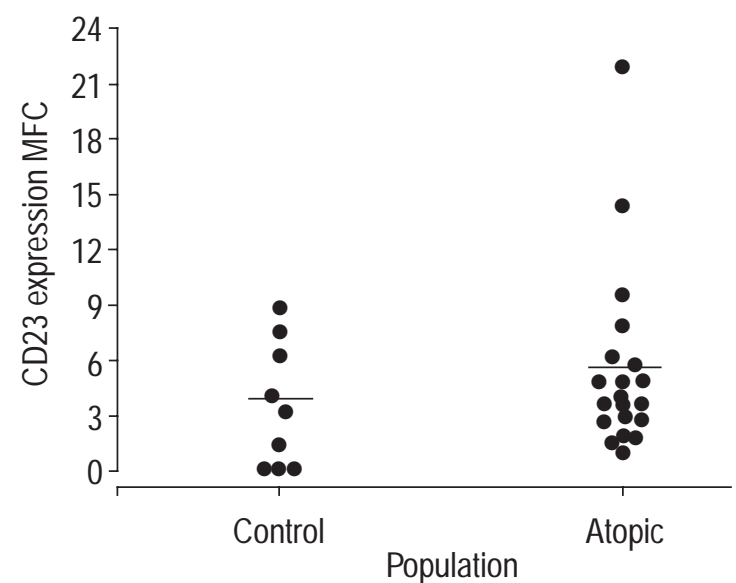

Fig. 2. - CD23 expression on eosinophils from atopic individuals and controls. Horizontal bars represent mean values. MFC: mean fluorescence channel.

Mac-1 expression, but not in VLA-4 expression ( $\mathrm{p}>0.1$ ), in both controls and atopic individuals, whereas no changes were detected in the presence of the control antihuman Mabs to CD45 ( $>0.05$ for all) (fig. 4). The

a)

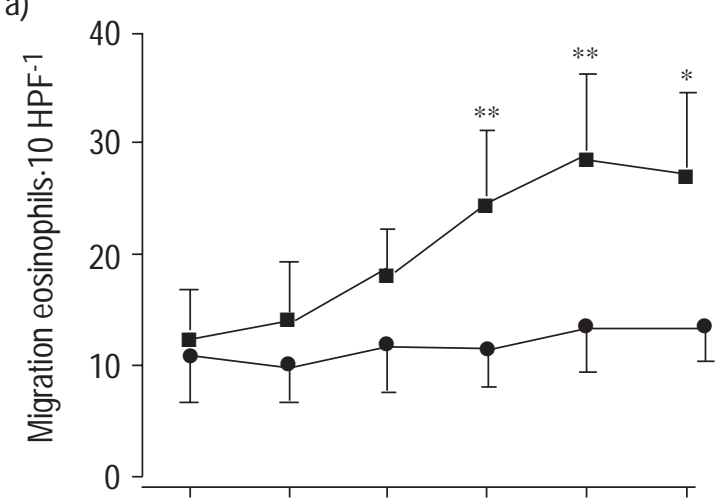

b)

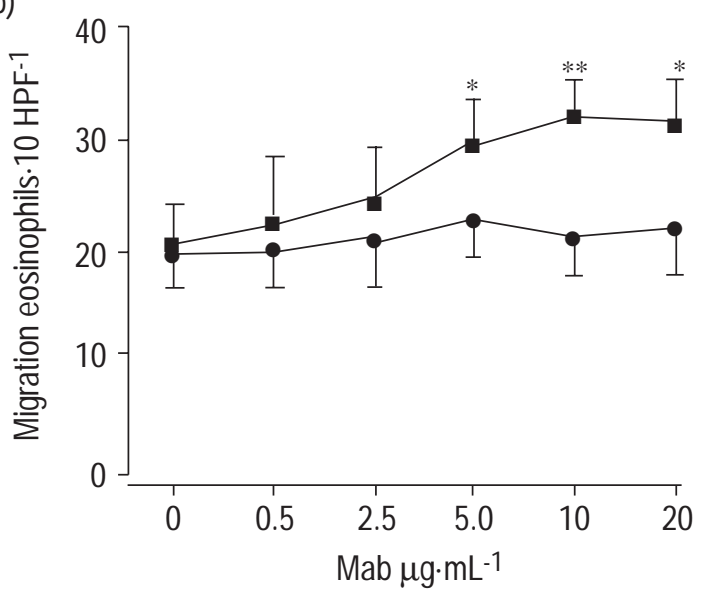

Fig. 3. - Evaluation of eosinophil migration through human umbilical vein endothelial cells towards $0.1 \mu \mathrm{g} \cdot \mathrm{mL}^{-1}$ complement factor $5 \mathrm{a}$ after stimulation of the immunoglobulin E low-affinity receptor with different concentrations of antihuman monoclonal antibodies (Mabs) to CD23 $(\square)$ or negative control antihuman Mabs to CD45 (O) in: a) controls; and b) atopic individuals. Data are presented as mean \pm SEM and represent the results of experiments performed with eosinophils obtained from five controls and eight atopic individuals. HPF: high-power field; $*$ : $\mathrm{p}<0.05$; $* *$ : $\mathrm{p}<0.01$. 
a)

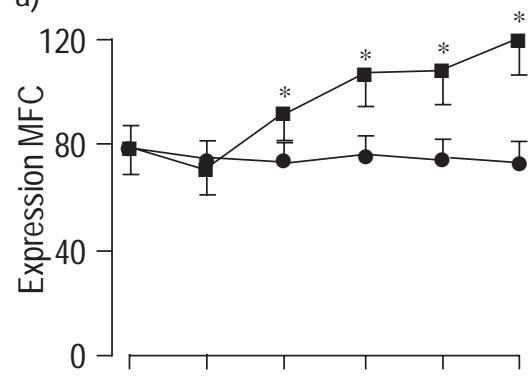

d)

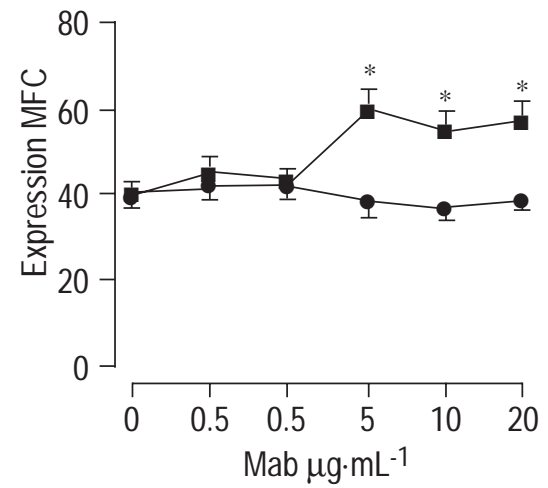

b)

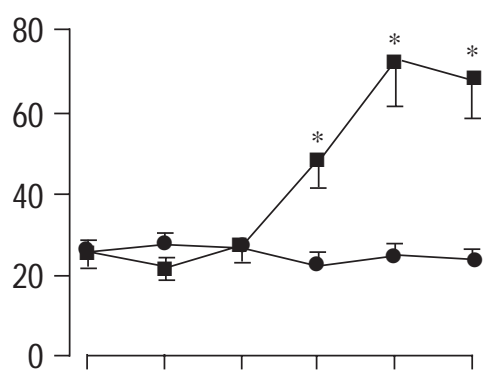

e)

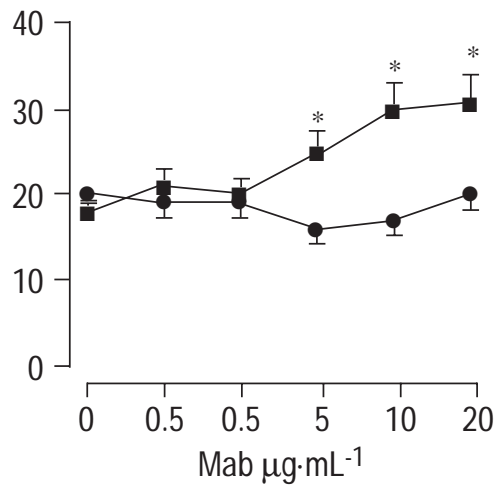

c)

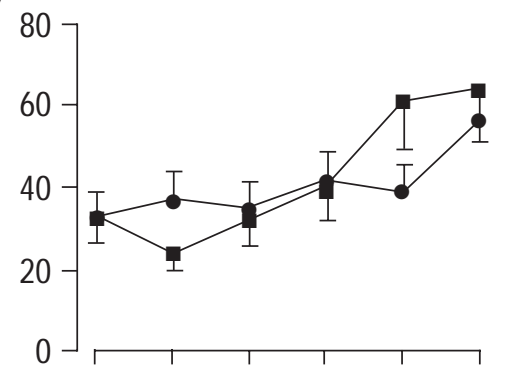

f)

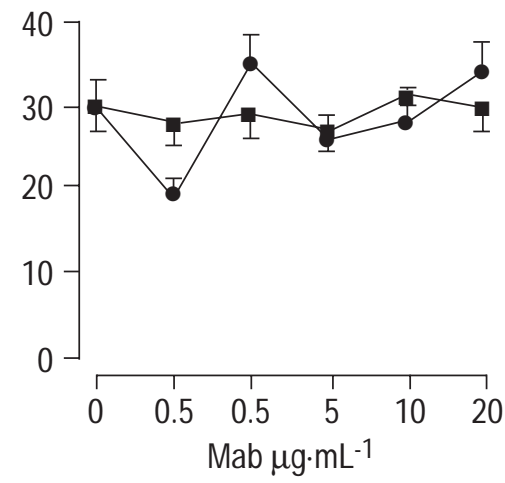

Fig. 4. - Upregulation of eosinophil adhesion molecules (a, d) late function antigen-1; b, e) Mac-1; c, f) very late activation antigen-4) by immunoglobulin E low-affinity receptor stimulation with different concentrations of antihuman monoclonal antibodies (Mabs) to CD23 ( $\boldsymbol{\square}$ ) or CD45 (O) in: a-c) five atopic individuals; and $\mathrm{d}-\mathrm{f}$ ) five controls. Data are presented as mean $\pm \mathrm{SEM}$. MFC: mean fluorescence channel. ${ }^{*}$ : $\mathrm{p}<0.05$.

antihuman Mab to CD23-induced increase in LFA-1 expression reached statistical significance at Mab concentrations of $5 \mu \mathrm{g} \cdot \mathrm{mL}^{-1}$ in atopic individuals and of 10 $\mu \mathrm{g} \cdot \mathrm{mL}^{-1}$ in controls (fig. $4 \mathrm{a}$ and d). The increase in Mac-1 expression reached statistical significance at Mab concentrations of $10 \mu \mathrm{g} \cdot \mathrm{mL}^{-1}$ in both atopic individuals and controls (figs. $4 \mathrm{~b}$ and e).

Adhesion receptor activity and eosinophil migration through human umbilical vein endothelial cells

In order to evaluate the functional role of the different adhesion molecules in modulating cell migration, CD23stimulated eosinophils from five atopic individuals were preincubated with blocking Mabs directed against LFA-1 (CD11a), Mac-1 (CD11b) or VLA-4 (CD49d), or with a mouse IgG, as isotype control, and tested in the chemotaxis assay using C5a as chemotactic agent. Eosinophil migration through HUVECs was totally inhibited by antihuman Mabs to CD11a (28 \pm 4 versus $6 \pm 2$ eosinophils. 10 $\mathrm{HPF}^{-1}$ for controls versus atopic individuals, $\left.\mathrm{p}=0.001\right)$, and

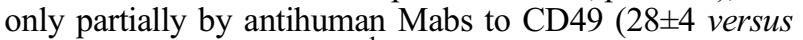
$15 \pm 6$ eosinophils $\left.10 \mathrm{HPF}^{-1}, \mathrm{p}<0.05\right)$, whereas antihuman Mabs to CD11b had no modifying effect on cell locomotion ( $\mathrm{p}>0.1$ ) (fig. 5).

\section{Discussion}

Evaluating partially purified blood eosinophils in vitro, it was demonstrated that unstimulated cells from atopic asthmatic subjects show a significantly higher cell migration rate and increased expression of LFA-1 compared to eosinophils from controls. No differences in Mac-1 or VLA-4 expression were observed. Eosinophils from most controls and all atopic individuals showed similar CD23 expression by fluorescence-activated cell sorting (FACS) analysis, and cell stimulation with anti-IgE low-affinity receptor Mabs enhanced, in a dose-dependent manner, eosinophil migration through HUVECs and LFA1 and Mac-1 (but not VLA-4) expression in both controls and atopic individuals. Finally, eosinophil migration through HUVECs was totally inhibited by the antihuman Mabs to LFA-1 and partially by the antihuman Mabs to VLA-4.

The finding that eosinophil migration and LFA-1 expression were increased in atopic asthmatic subjects is consistent with previous reports and with the concept that "preactivation" of circulating polymorphonuclear leukocytes occurs in allergic asthma [21, 22]. These biological properties of circulating eosinophils may, at least partially, explain the substantial migration of these cells into target tissue that occurs during acute asthma attacks and shortly after natural or experimental allergen exposure [23].

Cytokines and chemokines are able to preactivate eosinophils and increase adhesion molecule expression and cell locomotion [3-7]. In the present study it was also demonstrated that stimulation of FceRII, with antihuman Mabs to CD23 enhanced eosinophil migration through HUVECs and adhesion molecule (LFA-1 and Mac-1) expression.

Although eosinophils also display other IgE receptors,

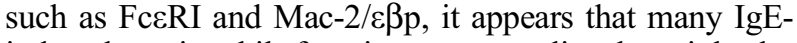
induced eosinophil functions are mediated mainly by 


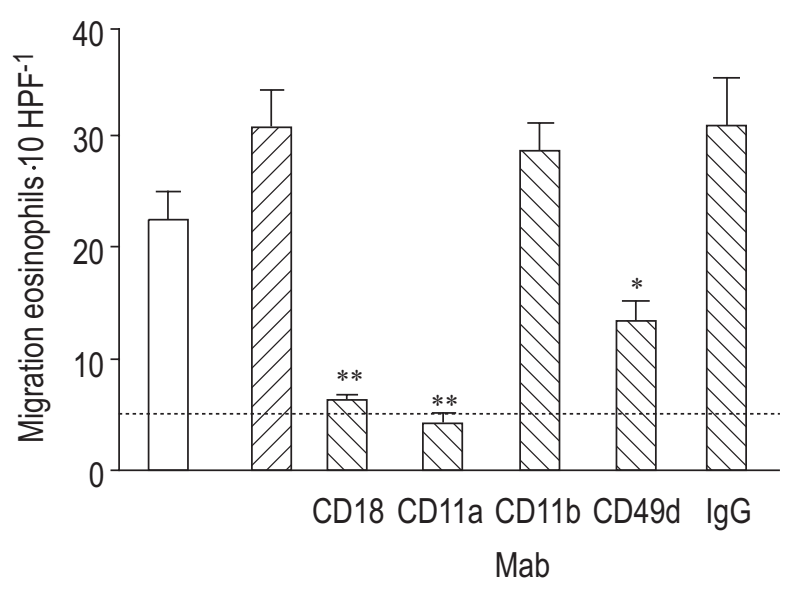

Fig. 5. - Inhibition of eosinophil chemotaxis through human umbilical vein endothelial cells towards $0.1 \mu \mathrm{g} \cdot \mathrm{mL}^{-1}$ by the blocking antihuman monoclonal antibodies (Mabs) to late function antigen-1 (CD11a), Mac1 (CD11b), very late activation antigen-4 (CD49d) and $\beta_{2}$ integrins (CD18) or with a mouse immunoglobulin $\mathrm{G}(\mathrm{IgG})$ as isotype control (- -: random migration). $\square$ : unstimulated cells; $\mathbb{Z}$ : cells stimulated with 5 $\mu \mathrm{g} \cdot \mathrm{mL}^{-1}$ antihuman Mab; $\mathbb{\mathbb { N }}$ : cells stimulated with antihuman Mab CD23 and incubated with different blocking Mabs. Data are presented as mean \pm SEM and represent the results of experiments performed with eosinophils obtained from five atopic individuals. HPF: high-power field. $*$ : $\mathrm{p}<0.05 ; * *: \mathrm{p}<0.01$.

FceRII/CD23 [9]. In addition, the demonstration that, in atopic patients, greater LFA-1 expression corresponds to disease severity and to higher serum levels of allergenspecific IgE [8] further supports the hypothesis of a significant role of FceRII in allergic asthma. In contrast with a recent paper showing, by flow cytometry, no CD23 expression on eosinophils isolated from atopic subjects [10], detectable CD23 was found on eosinophils from all atopic subjects and the majority of the controls in the present study. Patient selection and/or methodological differences may account for the discrepancy in results between the present results and those previously reported [24].

Only eosinophils from controls showing CD23 expression by FACS analysis were used in the CD23 stimulation experiments; these responded in a dose-dependent manner to antihuman Mabs to CD23 stimulation by increasing both LFA-1 and Mac-1 expression. The greater effect of anti-CD23 on adhesion molecule expression on eosinophils from controls than atopic individuals could be due to the fact that eosinophils from atopic individuals are in an activated state [5] and their capacity to increase adhesion molecule expression is almost saturated. Although a dose/ response effect of CD23 stimulation on both eosinophil migration and adhesion molecule expression were obtained, no correlation between these biological functions was observed in controls and atopic individuals. As demonstrated for other surface molecules, receptor functions are related not only to the "amounts" of molecules expressed but also to their biological properties (affinity, avidity state, etc.) [8].

Although stimulation of FceRII induced an increase in LFA-1 and Mac-1 adhesion molecule expression, but not in VLA-4, the experiments performed in the present study with blocking Mabs suggest that, in addition to LFA-1, VLA-4 but not Mac-1 is involved in eosinophil transendothelial migration. LFA-1 is the adhesion molecule which is specifically involved in eosinophil migration through the endothelium $[25,26]$ whereas VLA-4 appears to mainly determine the initial adherence process to the vessel wall, allowing the cells to slow down in the bloodstream [27, 28]. Mac-1 was not efficient in the present experimental system in mediating eosinophil transendothelial migration. Indeed, the demonstration that, in asthmatic patients, Mac-1 expression is increased in bronchial eosinophils, as compared to blood eosinophils from the same subjects [29], suggests its involvement in processes that follow transendothelial migration, e.g. interaction with other airway cells in the tissues.

Adhesion mechanisms can be upregulated through increased molecule expression on the cell membrane or through conversion of the molecule from a "low" to a "high" avidity state.

Modifications of LFA-1 and Mac-1 expression, observed in the present study following FceRII stimulation, appear to be related, at least in part, to increased molecular density on the cell membrane. These changes were detected by flow cytometry $2-4 \mathrm{~h}$ after stimulation, a period of time typical of that required for the regulation of surface adhesion receptor density at the messenger ribonucleic acid level $[28,30]$. In addition to increased molecular density, qualitative changes in adhesion molecule function, which occur on a much shorter timescale (minutes), could also be involved in the observed enhancement of eosinophil migration through HUVECs $[28,30]$.

In summary, in both atopic and control subjects, the functional presence of immunoglobulin E low-affinity receptor on blood eosinophils and its involvement in regulating the transendothelial trafficking of eosinophils was demonstrated.

\section{References}

1. Kay AB. Asthma and inflammation. $J$ Allergy Clin Immunol 1991; 87: 893-907.

2. Berman JS, Weller PF. Airway eosinophils and lymphocytes in asthma: birds of a feather? Am Rev Respir Dis 1992; 145: 1246-1248.

3. Resnick MB, Weller PF. Mechanisms of eosinophil recruitment. Am J Respir Cell Mol Biol 1993; 8: 349-355.

4. Hartnell A, Moqbel R, Walsh GM, Bradley B, Kay AB. $\mathrm{Fc} \gamma$ and CD11/CD18 receptor expression on normal density and low density human eosinophil. Immunology 1990; 69: 264-270.

5. Sehmi R, Wardlaw AJ, Cromwell O, Kurihara K, Waltmann P, Kay AB. Interleukin-5 selectively enhance the chemotactic response of eosinophils obtained from normal but not eosinophilic subjects. Blood 1992; 79: 2952-2959.

6. Das AM, Flower RJ, Peretti M. Eotaxin-induced eosinophil migration in the peritoneal cavity of ovalbumin-sensitized mice. J Immunol 1997; 159: 1466-1473.

7. Ebisawa M, Yamada T, Bickel C, Klunk D, Shleimer RP. Eosinophil transendothelial migration induced by cytokines. III. Effect of the chemokine RANTES. J Immunol 1994; 153: 2153-2160.

8. Lantero S, Alessandri G, Spallarossa D, Scarso L, Rossi GA. LFA-1 expression by blood eosinophils is increased in atopic asthmatic children and is involved in eosinophil locomotion. Eur Respir J 1998; 12: 1094-1098.

9. Arock M, Le Goff L, Bécherel P-A, Dugas B, Debré P, 
Mossalavi MD. Involvement of FceRII/CD23 and L-arginine dependent pathway in IgE-mediated activation of human eosinophils. Biochem Biophys Res Commun 1994; 202: 265-271.

10. Kita H, Kaneko M, Bartemes KM, et al. Does IgE bind to and activate eosinophils from patients with allergy? $J$ Immunol 1999; 162: 6901-6911.

11. Capron M, Truong MJ, Aldebert D, et al. Heterogeneous expression of CD23 epitopes by eosinophils from patients: relationship with IgE-mediated functions. Eur J Immunol 1991; 21: 2423-2429.

12. Gounni AS, Larnkhioued B, Ochiai K, et al. High affinity IgE receptor on eosinophils is involved in the defence against parasites. Nature 1994; 367: 183-186.

13. American Thoracic Society. Definition and classification of chronic bronchitis, asthma and emphysema. Am Rev Respir Dis 1962; 85: 762-768.

14. Gartner I. Separation of human eosinophils in density gradients of polyvinylpyrrolidone-coated silica gel (Percoll). Immunology 1980; 40: 133-136.

15. Gimbrone MA Jr, Cotran RS, Folkman J. Human vascular endothelial cells in culture. J Cell Biol 1974; 6: 673-684.

16. Lantero S, Sacco O, Scala C, Morelli MC, Rossi GA. Eosinophil locomotion and the release of IL-3 and IL-5 by allergen-stimulated mononuclear cells are effectively downregulated in vitro by budesonide. Clin Exp Allergy 1996; 26: 656-664.

17. Mawhorter SD, Stephany DA, Ottesen EA, Nutman TB. Identification of surface molecules associated with physiologic activation of eosinophils: application of whole blood flow cytometry to eosinophils. $J$ Immunol 1996; 156: 4851-4858.

18. Spurzem JR, Sacco O, Rossi GA, Beckman JD, Rennard SI. Regulation of MHC class II gene expression on bovine bronchial epithelial cells. J Lab Clin Med 1992; 120: 94-102.

19. Muirhead KA, Schmitt TC, Muirhead AR. Determination of linear fluorescence intensities from flow cytometric data accumulated with logarithmic amplifiers. Cytometry 1983; 3: 251-256.

20. Silvestri M, Oddera S, Spallarossa D, Frangova Yourukova V, Rossi GA. In childhood asthma the degree of allergen-induced T-lymphocyte proliferation is related to serum $\operatorname{IgE}$ levels and to blood eosinophilia. Ann Allergy Asthma Immunol 2000; 84: 426-432.

21. Prin L, Capron M, Tonnel AB, Bletry O, Capron A. Heterogeneity of human peripheral blood eosinophils: variability in cell density and cytotoxic ability in relation to the level and the origin of hypereosinophilia. Int Arch Allergy Appl Immunol 1983; 72: 336-346.

22. Shult PA, Lega M, Jaridi S, et al. The presence of hypodense eosinophils and diminished chemolurninescence response in asthma. J Allergy Clin Immunol 1988; 81: 429-437.

23. Kita H, Adolphson CR, Gleich GJ. Biology of eosinophils. In: Middleton E Jr, Reed CE, Ellis EF, Adkinson NF Jr, Yunginger JW, Busse WW, eds. Allergy: Principle and Practice. St Louis, MO, Mosby-Year Book, 1998; pp. 242-247.

24. Sano H, Munoz NM, Sano A, et al. Upregulated surface expression of intracellularly sequestered Igepsilon receptors (FcepsilonRII/CD23) following activation in human peripheral blood eosinophils. Proc Assoc Am Physicians 1999; 111: 82-91.

25. Nakao A, Nakajima $H$, Tomioka $H$, Nishimura $T$, Iwamoto I. Induction of T-cell tolerance by pretreatment with anti-ICAM-1 and anti-lymphocyte functionassociated antigen-1 antibodies prevent antigen-induced eosinophil recruitment into the mouse airways. J Immunol 1994; 153: 5819-5825.

26. Bloemen PGM, Buckley TL, van der Tweel MC, et al. LFA-1, and not Mac-1, is crucial for the development of hyperreactivity in a murine model of nonallergic asthma. Am J Respir Crit Care Med 1996; 153: 521-529.

27. Pretolani M, Ruffié C, Lapa e Silva J-R, Lobb RR, Vargaftig BB. Antibody to very late activation antigen 4 prevents antigen-induced bronchial hyperreactivity and cellular infiltration in the guinea pig airways. J Exp Med 1994; 180: 795-805.

28. Johnson FL, Haraldsen G, Aanesen JP, Haye R, Brandtzaeg P. Eosinophil infiltration is related to increased expression of vascular cell adhesion molecule-1 in nasal polyps. Am Respir Cell Mol Biol 1995; 12: 624632.

29. Mengelers HJ, Maikoe T, Brinkman L, Hooibrink B, Lammers JW, Koenderman L. Immunophenotyping of eosinophils recovered from blood and BAL of allergic asthmatics. Am J Respir Crit Care Med 1994; 149: 345351.

30. Bloom M, Tool ATJ, Kok PTM, Koendermann L, Roos D, Vahoeven AJ. Granulocytemacrophage colony-stimulating factor, interleukin-3 (IL-3) and IL-5 greatly enhance the interaction of human eosinophils with opsonized particles by changing the affinity of complement receptor type 3. Blood 1994; 83: 2978-2984. 